\title{
Maternal insulin treatment improves pre-implantation embryo development in diabetic rats
}

\author{
R.De Hertogh, I. Vanderheyden, S. Pampfer, D. Robin and J. Delcourt \\ Physiology of Human Reproduction Research Unit, University of Louvain, Brussels, Belgium
}

\begin{abstract}
Summary. Pre-implantation embryos were recovered from control, diabetic and insulin-treated diabetic rats on day 5 of pregnancy. Compared to control animals, diabetic rats had a $20 \%$ reduction in the number of embryos per rat and blastocysts recovered from diabetic rats showed a $19 \%$ decrease in total cell number. The cellular decrease observed in blastocysts was mainly at the expense of the inner cell mass. Insulin replacement therapy was started on day 1 of pregnancy and normalized the glycaemia of diabetic rats but failed to raise the number of embryos per rat toward the control value. Insulin treatment, however, fully restored the normal cell num-
\end{abstract}

ber in both the inner cell mass and trophectoderm of blastocysts. The dead cell index, which was significantly elevated in the inner cell mass of blastocysts from diabetic rats, also returned to the control value following insulin treatment. Our data suggest that diabetes-induced impairment of pre-implantation development can be partly prevented by insulin treatment started shortly after conception.

Key words: Rat, diabetes mellitus, insulin, blastocyst, pre-implantation development.
Increasing evidence supports the hypothesis that pre-implantation embryo development is impaired by maternal diabetes mellitus. In mice, blastocysts recovered from diabetic females on day 4 had fewer cells and a lower protein synthesis rate than blastocysts from control females [1]. Two-cell embryos from diabetic mice and cultured in vitro demonstrated a decreased rate of development into blastocysts when compared to control embryos [2]. In rats, maternal diabetes has been correlated with a decreased rate of implantation [3] and pre-implantation embryos collected from diabetic females on day 5 presented a marked delay in development [4]. Further investigation showed that the maternal diabetes was selectively impairing the proliferation of the inner cell mass (ICM) cells in rat blastocysts [5]. In vitro, the presence of glucose in high concentration in the culture medium of rat blastocysts was found to have an inhibitory effect on further development, with again a larger reduction in ICM proliferation than in trophectoderm (TE) cells [6].

Administration of insulin proved successful in correcting some of the developmental parameters affected by maternal diabetes during the pre-implantation period $[1$, 7]. However, whether insulin treatment could normalize the total cell number and the partitioning of these cells between ICM and TE in blastocysts has never been investigated. The present work was carried out to address this issue.

\section{Materials and methods}

Induction of the diabetic state and insulin treatment

Adult Wistar rats were rendered diabetic by administering a single intravenous injection of streptozotocin $(50 \mathrm{mg} / \mathrm{kg}$, Zanossar; Upjohn Co., Kalamazoo, Mich., USA) to fasted rats as previously described [8]. Control females were injected with vehicle alone. Diabetic females with a glycosuria above $2 \%$, as tested with TesTape (Eli Lilly Co., Indianapolis, Ind., USA), were mated overnight with normal males and checked on the following morning for a vaginal plug (day 1 of pregnancy). A group of diabetic rats was placed on insulin therapy immediately after pregnancy had been established.

Table 1. Plasma glucose concentration, plasma insulin concentration and total cell number of blastocysts in control, diabetic and insulin-treated diabetic rats

\begin{tabular}{llll}
\hline & $\begin{array}{l}\text { Control } \\
\text { rats }\end{array}$ & $\begin{array}{l}\text { Diabetic } \\
\text { rats }\end{array}$ & $\begin{array}{l}\text { Insulin-treated } \\
\text { diabetic rats }\end{array}$ \\
\hline Number of rats & 15 & 11 & 10 \\
Glucose $(\mathrm{mmol} / \mathrm{l})$ & $5.5 \pm 1.0$ & $23.6 \pm 5.3^{\mathrm{a}}$ & $6.4 \pm 2.3$ \\
Insulin $(\mathrm{nmol} / \mathrm{l})$ & $0.5 \pm 0.2$ & $0.2 \pm 0.1$ & $2.7 \pm 1.9^{\mathrm{a}}$ \\
Number of blastocysts & 30 & 51 & 52 \\
Total cell number & $35.1 \pm 10.8$ & $28.4 \pm 6.6^{\mathrm{a}}$ & $33.7 \pm 7.5$ \\
\hline
\end{tabular}

Plasma concentration values and cell number values are shown as mean \pm SD.

${ }^{a} p<0.01$ by analysis of variance 


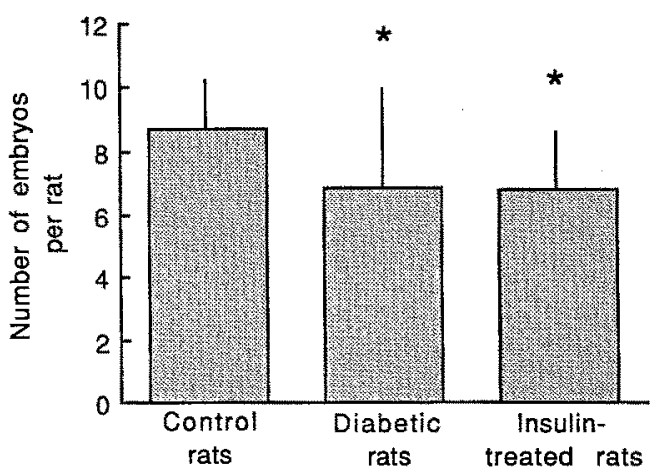

Fig. 1. Number of embryos recovered per rat on day 5 of pregnancy from control, diabetic and insulin-treated diabetic rats. Numbers of rats were as in Table 1 . Values are shown as mean \pm SD. ${ }^{*} p<0.01$ vs control value

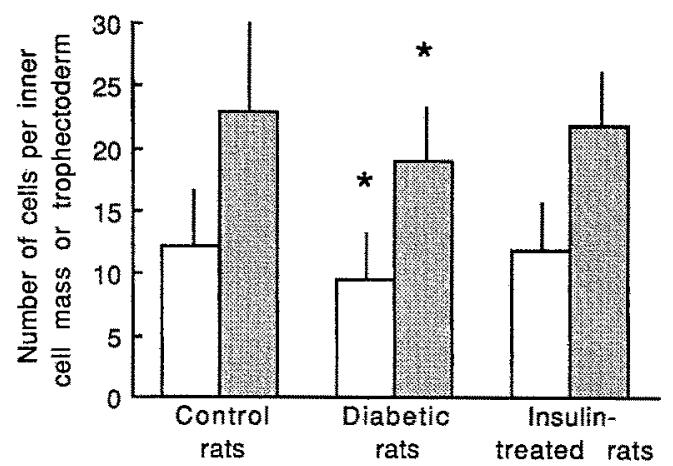

Fig. 2. Number of cells in the inner cell mass (empty columns) and trophectoderm (filled columns) of blastocysts recovered from control, untreated diabetic and insulin-treated diabetic rats. Numbers of blastocysts were as in Table 1 . Values are shown as mean \pm SD. ${ }^{*} p<0.01$ vs control value

Subcutaneous injections of insulin (Novo Lente; Novo Nordisk, Bagsværd, Denmark) were given at a dose of 2 IU on the morning of day $1,3 \mathrm{IU}$ on the evening of day 1 and then 4 to $6 \mathrm{IU}$ on the evening of days 2,3 and 4 , to achieve a level of glycosuria below $0.5 \%$. Control and untreated diabetic females received injections of $0.9 \%$ $\mathrm{NaCl}$. The animals were allowed free access to food and water until the time of killing.

\section{Embryo collection}

On the morning of day 5 , approximately $16 \mathrm{~h}$ after the last insulin injection, the uterine horns of killed females were flushed with prewarmed Ham-F10 medium (041-01550; Gibco BRL, Gaithersburg, Md., USA) as detailed elsewhere [4]. The embryos were immediately observed by inverted phase-contrast microscopy and classified as morulae or blastocysts as previously described [4]. The blastocysts were further investigated by means of a differential staining technique that allows for the separate counting of ICM and TE cells in individual embryos [9]. Cells containing scattered nuclear fragments were considered as dead cells [5]. Determination of plasma glucose and insulin concentrations was performed on day 5 only in order to avoid unnecessary stress to the animals. Blood samples were collected immediately after embryo retrieval. The glucose level was measured with a Glucoscot photometer (6T-4310; Daiichi Kagaku, Kyoto, Japan) and the insulin concentration was assayed by means of an insulin RIA that gave similar results irrespective of whether the rat standard preferred in the present work or a human standard was used (J.C.Henquin, Diabetes Unit, University of Louvain, Belgium). Lower sensitivity limit of the RIA was $20 \mathrm{pmol} / 1$ in plasma.

\section{Statistical analysis}

Statistical significance of the differences found between control, diabetic and insulin-treated diabetic data was evaluated by one-way analysis of variance.

\section{Results}

Administration of insulin to the diabetic rats resulted in a rapid decrease or disappearance of glycosuria over the first 5 days of pregnancy (data not shown), and in the complete correction of glycaemia on day 5. At that time, no apparent difference was found between control and insulin-treated diabetic rats with respect to the plasma glucose concentration (Table 1). Glucose levels in untreated diabetic females were significantly higher $(p<0.01)$ than that in the two other groups. Compared to control rats, the insulin therapy induced a significant increase $(p<0.01)$ in the plasma insulin concentration of treated females (Table 1 ).

Insulin therapy to diabetic rats did not restore the normal rate of embryo recovery on day 5 . The mean number of embryos per female was reduced by $20 \%$, and thus significantly lower $(p<0.01)$, in both diabetic and insulin-treated diabetic rats when compared to control animals (Fig.1). The percentage of embryos that had reached the blastocyst stage on day 5 was $90 \%$ in the control group and $80 \%$ in both diabetic and insulin-treated diabetic groups.

When assessed for the total number of cells, a significant difference was found between blastocysts from normal and diabetic females $(p<0.01)$ (Table 1$)$. Blastocysts from diabetic rats were found to contain about $19 \%$ fewer cells than those from control animals. Insulin treatment resulted in the complete correction of this developmental parameter and the total cell number in blastocysts from insulintreated diabetic rats was the same as that from control rats.

Differential cell counting revealed that the negative impact of maternal diabetes was more pronounced on the proliferation of ICM cells than TE cells (Fig. 2). Blastocysts recovered from diabetic females had about $23 \%$ fewer ICM cells and $16 \%$ fewer TE cells than blastocysts from control rats $(p<0.01)$. Differential scoring of ICM and TE cells of blastocysts from insulin-treated diabetic rats showed that normal ICM and TE cell numbers were restored by insulin treatment. Neither the total cell number nor the numbers of ICM and TE cells in blastocysts were found to correlate with the level of glucose or insulin in the plasma of diabetic or insulin-treated diabetic rats.

Dead cells were found significantly more frequently in the ICM of blastocysts from diabetic rats ( 6 of 490 cells) than from control ( 0 of 366 cells) and insulin-treated diabetic rats ( 0 of 619 cells) $(p<0.05)$.

\section{Discussion}

Daily insulin treatment started on day 1 of pregnancy has previously been shown to fully normalize the glycaemia of diabetic rats throughout gestation [10]. Under these conditions, our data demonstrated that insulin replacement therapy was successful in restoring normal cell proliferation both in the ICM and in the TE of blastocysts exposed to maternal diabetes. The occurrence of cell death in the ICM of these embryos was also normalized by insulin treatment. Starting the administration of insulin after 
pregnancy was confirmed, however, failed to compensate for perturbations which might have been diabetes-induced at the time of ovulation and fertilization. Previous studies have shown that diabetic rats ovulated fewer oocytes than control females [11] and this could explain why both untreated [5] and insulin-treated diabetic rats had fewer embryos than controls animals on day 5 .

Since diabetes-induced perturbations of early pregnancy are most probably due to a combination of different factors [12] it is difficult to determine whether the normalization of blastocyst development was due to the direct action of insulin supplemented to the diabetic females or attributable to the correction of maternal metabolism. Since plasma insulin was increased in insulin-treated diabetic rats when compared to control values, it is possible that preimplantation embryos recovered from these females were exposed to highlevels of insulin in their oviductal or uterine environment. Several lines of evidence have pointed to a direct role of insulin in the regulation of pre-implantation embryo development. Insulin has been found to increase the metabolism [13], the cell proliferation [14] and the implantation rate [15] of mouse blastocysts. Stimulation of cell proliferation in these embryos was entirely due to an increase in their ICM cell number [16]. In rat blastocysts, insulin was found to either stimulate or inhibit cell proliferation depending on the concentrations of insulin and glucose in the culture medium [6]. The positive/negative effects of insulin were mainly observed on the ICM of these blastocysts, confirming the ICM cells as the primary target of insulin action on embryos prior to implantation.

Previous observations have also demonstrated the specific sensitivity of the ICM cells to maternal diabetes [5]. Since ICM cells give rise to all the germ layers of the developing fetus, it has been suggested that a high frequency of cell death in the ICM of blastocysts might contribute to the increased rate of resorptions and malformations observed during diabetic pregnancy. The present data support the hypothesis that insulin therapy, which decreases the frequency of post-implantation anomalies [17] is partially mediated by the normalization of ICM and TE cell proliferation in blastocysts. Whether this restoration is due to the inhibition of diabetes-induced cell death or to the stimulation of cell division by insulin is still unclear. This hormone might also act through other mechanisms which regulate blastocyst growth since enzymatic systems such as $\mathrm{Na}^{+}-\mathrm{K}^{+}$ATPase, which are instrumental to blastocyst cavitation and expansion $[18,19]$, have been shown to be dependent on insulin [20].

In conclusion, the present data have shown that the alteration of blastocyst development observed in diabetic rats is a reversible situation correctable by insulin replacement therapy.

Acknowledgements. This work was supported by grant $\mathrm{n}^{\circ} 3-4590-88$ of the Fonds de la Recherche Scientifique Médicale. We gratefully acknowledge the collaboration of Drs. J. C.Henquin and J.Decoster. The technical assistance of Mr. E. Dufrasnes and Ms. A.M.Delait has been greatly appreciated.

\section{References}

1. Beebe LFS, Kaye PL (1991) Maternal diabetes and retarded preimplantation development of mice. Diabetes 40: 457-461
2. Diamond MP, Moley KH, Pellicer A, Vaughn WK, De Cherney AH (1989) Effects of streptozotocin- and alloxan-induced diabetes mellitus on mouse follicular and early embryo development. J Reprod Fert 86: 1-10

3. De Hertogh R, Vanderheyden I, Glorieux B, Ekka E (1989) Oestrogen and progestogen receptors in endometrium and myometrium at the time of blastocyst implantation in pregnant diabetic rats. Diabetologia 32: 568-572

4. Vercheval M, De Hertogh R, Pampfer S et al. (1990) Experimental diabetes impairs rat embryo development during the preimplantation period. Diabetologia 33:187-191

5. Pampfer S, De Hertogh R, Vanderheyden I, Michiels B, Vercheval M (1990) Decreased inner cell mass proportion in blastocysts from diabetic rats. Diabetes $39: 471-476$

6. De Hertogh R, Vanderheyden I, Pampfer S, Robin D, Dufrasne E, Delcourt J (1991) Stimulatory and inhibitory effects of glucose and insulin on rat blastocyst development in vitro. Diabetes 40 ; $641-647$

7. Diamond MP, Harbert-Moley K, Logan J et al. (1990) Manifestation of diabetes mellitus on mouse follicular and pre-embryo development: effects of hyperglycemia per se. Metabolism 39:220 224

8. Ekka E, Vanderheyden I, De Hertogh R (1981) Oestrogen receptors and oestrogen-induced protein synthesis in the uterus of diabetic rats. Diabetologia 20: 578-582

9. Pampfer S, Vanderheyden I, Michiels B, De Hertogh R (1990) Cell allocation to the inner cell mass and the trophectoderm in rat embryos during in vivo preimplantation development. Roux"s Arch Dev Biol 198: 257-263

10. Robinson J, Canavan JP, El Haj AJ, Goldspink DF (1988) Maternal diabetes in rats: effects on placental growth and protein turnover. Diabetes 37: 1665-1670

11. Giavini E, Broccia ML, Prati M, Roversi GD, Vismara C (1986) Effects of streptozotocin-induced diabetes on fetal development of the rat. Teratology $34: 81-88$

12. Sadler TW, Hunter ES, Wynn RE, Phillips LS (1989) Evidence for multifactorial origin of diabetes-induced embryopathies. Diabetes 38: 70-74

13. Rao LV, Wikarczuk ML, Heyner S (1990) Functional roles of in sulin and insulin-like growth factors in preimplantation mouse embryo development. In Vitro Cell Dev Biol 26: 1043-1048

14. Gardner HG, Kaye PL (1991) Insulin increases cell number and morphological development in mouse preimplantation embryos in vitro. Reprod Fertil Dev 3: 79-91

15. Zhang X, Amstrong DT (1990) Presence of amino acids and insulin in a chemically defined medium improves development of 8 -cell rat embryos in vitro and subsequent implantation in vivo. Biol Reprod 42: 662-668

16. Harvey MB, Kaye PL (1990) Insulin increases the cell number of the inner cell mass and stimulates morphological development of mouse blastocysts in vitro. Development 110: 963-967

17. Eriksson U, Dahlström E, Larsson KS, Hellerström C (1982) Increased incidence of congenital malformations in the offspring of diabetic rats and their prevention by maternal insulin therapy. Diabetes $30: 1-6$

18. Wiley LM (1984) Cavitation in the mouse preimplantation embryo: $\mathrm{Na} / \mathrm{K}$ ATPase and the origin of nascent blastocoel fluid. Dev Biol 105:330-342

19. Manejwala FM, Cragoe EJ, Schultz RM (1989) Blastocoel expansion in the preimplantation mouse embryo: roles of extracellular sodium and chloride and possible apical routes of their entry. Dev Biol 133: 210-220

20. Moore RD (1983) Effects of insulin upon ion transport. Biochem Biophys Acta 737: 1-49

Received: 21 October 1991

and in revised form: 12 December 1991

Prof. R. De Hertogh

Physiology of Human Reproduction Research Unit

University of Louvain School of Medicine (OBST 5330)

53 Avenue E. Mounier

B-1200 Brussels, Belgium 